\title{
Evaluating combinatorial effects of galbanic acid and arsenic trioxide on ATL cells
}

\author{
Maryam Mahdifar ${ }^{1}$, Mehrdad Iranshahi ${ }^{1}$, Narges Valizadeh ${ }^{1}$, Marzieh Golizadeh ${ }^{1}$, Fatemeh \\ B. Rassouli ${ }^{2}$, and Houshang Rafatpanah ${ }^{1}$ \\ ${ }^{1}$ Mashhad University of Medical Sciences \\ ${ }^{2}$ Ferdowsi University of Mashhad
}

May 5, 2020

\begin{abstract}
Abstract Background and Purpose: Galbanic acid (GBA), a sesquiterpene coumarin compound isolated from Ferula species, has noticeable anti-cancer effects. In current research, we investigated effects of GBA in combination with arsenic trioxide (ATO) on MT-2 cells, an Adult T cell leukemia (ATL) cell line. ATL is a malignancy caused by human T cell leukemia virus type 1 (HTLV1). Experimental Approach: The MT-2 cells were treated with each agent alone at various concentrations. After determination of IC50 values, MT-2 cells were treated with $20 \mu \mathrm{M}$ GBA combined with $4 \mu \mathrm{M}$ ATO. The viability of MT-2 cells was evaluated by alamar blue assay and cell cycle distribution was assessed by PI staining. Furthermore, the activity of P-glycoprotein (P-gp) in the presence of GBA was studied by mitoxantrone efflux assay. To understand the molecular mechanisms of GBA+ATO treatment in MT-2 cells, the mRNA expression of RelA, p53, CDK4, c-MYC, c-FLIPL, and c-FLIPS was measured by real-time PCR. Key Results: GBA+ATO synergistically inhibited proliferation of MT-2 cells and induced apoptotic cell death. GBA and ATO also synergized to induce cell cycle arrest with an apparent sub-G1 cells accumulation. Rate of mitoxantrone accumulation in MT-2 cells was enhanced in the presence of GBA, indicating GBA has inhibitory effects on the functionality of the P-gp efflux pump. The real-time PCR analysis revealed that GBA+ATO combination downregulated the expression of p53, CDK4, c-FLIPL, and c-FLIPS. Statistical analysis revealed a significant relation between p53 expression and c-FLIPS. Conclusion and Implications: The GBA+ATO combination could be considered as a new therapeutic approach for ATL patients.
\end{abstract}

\section{Introduction}

ATL, a highly aggressive non-Hodgkin lymphoma that is usually accompanied by visceral involvement, is a peripheral $\mathrm{T}$ cell neoplasm associated with Human $\mathrm{T}$ cell leukemia virus type 1 (HTLV-1), a type C oncoretrovirus (Tsukasaki and Tobinai, 2012; Hermine et al., 2018). HTLV-1 oncoprotein Tax interacts with intracellular signaling pathways and modulates transcription of cellular genes involved in cell cycle progression, cell proliferation, and apoptosis resulting in immortalization and transformation of HTLV-1 infected cells and ATL pathogenesis (Tanaka et al., 1990; Ressler et al., 1997; Mulloy et al., 1998; Schmitt et al., 1998; Kashanchi and Brady, 2005; Matsuoka and Jeang, 2007; Zhang et al., 2017). In HTLV-1 infected cells, NF- $\varkappa \mathrm{B}$ is constitutively activated through Tax-dependent or -independent mechanisms and plays an important role in HTLV-1 oncogenesis and survival of HTLV-1 transformed T cells (Mori et al., 1999; Hironaka et al., 2004; Horie, 2007). Tax also contributes to the immortalization of HTLV-1 infected cells by transactivation of the c-MYC gene through the NF- $x$ B pathway (Duyao et al., 1992). The interaction between c-MYC and the HTLV-1 latency maintenance factor p30II enhances virus replication and oncogenesis (Romeo et al., 2015). About 30\% of patients with ATL carry p53 mutations (Portis et al., 2001). Tax inhibits p53 transcriptional function in infected cells, thereby leading to the progression of ATL (Ariumi et al., 2000; 
Zane et al., 2012). Tax also interacts with inhibitors of CDK4 activity, leading to activation of CDK4 and dysregulated $\mathrm{G}_{1} / \mathrm{S}$ progression of the cell cycle (Suzuki et al., 1996; Haller et al., 2000; Yoshida, 2001). Tax expressing HTLV-1 infected T cells also express a high level of c-FLIPL and c-FLIPS which are potent death receptor inhibitory proteins known as tumor progression factors and act as antiapoptotic proteins by inhibiting death receptor-mediated apoptosis (Djerbi et al., 1999; Krueger et al., 2006). These alterations may together result in the leukemogenesis of HTLV-1 infected cells and ATL development.

Although several therapeutic approaches targeting different cellular pathways involved in cell cycle progression and cell proliferation have been applied for ATL therapy, treatment of ATL continues to be a significant challenge. Currently, no standard treatment exists for patients with ATL and long term efficacy of current treatments is limited. ATL is still an aggressive and intractable disease that carries a poor prognosis because of chemo-resistance and immunosuppression which increases vulnerability to opportunistic infections (Kchour et al., 2013). Multidrug resistance represents a major obstacle to the effective treatment of ATL. Resistance to chemotherapy may be correlated with the presence of Multidrug resistance (MDR) proteins (Yasunami et al., 2007).

Treating HTLV-1 infected cells with arsenic trioxide (ATO) revealed that ATO has therapeutic potential for ATL treatment by inhibiting the proliferation of HTLV-1 infected T cells and inducing apoptotic cell death (Ishitsuka et al., 1998; Mahieux et al., 2001; Ishitsuka et al., 2002). Combination therapy with ATO for HTLV-1 infection, triggers degradation of tax oncoprotein and consequently inactivates NF- $x$ B signaling pathway, and induces cell death via cell cycle arrest and apoptosis induction (Bazarbachi et al., 1999; ElSabban et al., 2000). Recently, herbal medicines in combinations with anticancer agents have been found to have cancer preventative and therapeutic activities (Wang et al., 2012; Arslan et al., 2013). Galbanic acid (GBA), a sesquiterpene coumarin compound isolated from Ferula species, has been reported to have noticeable anti-tumor and anti-viral activities and can counteract cancer through apoptosis induction, P-gp inhibition, and anti-angiogenesis and anti-proliferative activities (Bedniak et al., 1967; Iranshahi et al., 2007; Hanafi-Bojd et al., 2011; Iranshahy and Iranshahi, 2011; Kim et al., 2011; Kasaian et al., 2014). To date, no studies have investigated the effects of GBA in ATL. Thus, the present study was designed to determine whether GBA in combination with ATO would improve the therapeutic efficacy against ATL.

\section{Materials and Methods}

\section{Isolation of GBA}

GBA (C24H30O5: 2-cyclohexene-1-butanoic acid) was extracted from the herbal roots of Ferula Szowitsiana over a previously described method (Iranshahi et al., 2007). This study did not require ethical approval.

\section{Cell culture}

The MT-2 cell line (a HTLV-1 transformed human T cell line) was cultured in RPMI 1640 (KBC, Iran) medium supplemented with $10 \%$ fetal bovine serum (Gibco, USA), 1\% penicillin/streptomycin (Capricorn, Germany), and $0.5 \%$ L- Glutamine (Serena, Germany) at $37^{\circ} \mathrm{C}$ with $5 \% \mathrm{CO}_{2}$ and a humidity of $96 \%$.

\section{Cytotoxicity assay}

The cytotoxicity of GBA and ATO was determined by alamar blue assay. The MT-2 cells were seeded at the density of $50 \times 10^{3}$ per well in a 96-well cell culture plate, and then treated with various concentrations of GBA $(5,10,20,40$, and $80 \mu \mathrm{M})$ and/or ATO (Sigma-Aldrich, St Louis, MO, USA) at the concentrations of 2, 4,8 , and $16 \mu \mathrm{M}$ for 24,48 , and $72 \mathrm{~h}$. The effect of GBA and/or ATO on the viability of MT-2 cells was then assessed by alamar blue assay (Sigma, Germany). Alamar blue solution $(0.15 \mathrm{mg} / \mathrm{ml})$ was incubated until a pink fluorescent resorufin was constituted. The optical density (O. D) was measured using a microplate 
reader (Epoch, BioTek, USA) at $600 \mathrm{~nm}$ and cell viability was calculated. When the $\mathrm{IC}_{50}$ values of GBA and ATO were determined, the MT-2 cells were treated with GBA and ATO, alone or in combination, at concentrations lower than $\mathrm{IC}_{50}$ with weak cytotoxic effects, and then the cell viability was assessed with alamar blue assay.

\section{Cell cycle analysis}

To study the cell cycle distribution in GBA+ATO treated cells, the MT-2 cells were seeded at the density of $40 \times 10^{4}$ per well in a 6 -well cell culture plate and treated with $20 \mu \mathrm{M}$ GBA and $4 \mu \mathrm{M}$ ATO alone or in combination at equal concentrations for $48 \mathrm{~h}$. Then, the treated cells were washed and resuspended in 480 $\mu \mathrm{l}$ of PI solution $(100 \mu \mathrm{g} / \mathrm{mL}$ PI, $0.1 \%$ Triton X-100, and $0.1 \%$ sodium citrate in PBS) (Sigma, Germany) and incubated for $30 \mathrm{~min}$ at $37^{\circ} \mathrm{C}$ in dark. Then the flow cytometric analysis was performed with the FACS Calibur flow cytometer (BD Biosciences, USA) using FL2 filter. Data obtained from flow cytometric analysis of cell cycle was then analyzed in winMDI data analysis software version 2.8 .

\section{Efflux assay}

To study the activity of P-gp in the presence of GBA, the MT-2 cells were seeded at the density of $40 \times 10^{4}$ per well in a 6-well cell culture plate and treated with $20 \mu \mathrm{M}$ GBA for $48 \mathrm{~h}$. After centrifugation, the cell pellets were resuspended in mitoxantrone $(10 \mu \mathrm{M})$ and incubated for $30 \mathrm{~min}$ at $37^{\circ} \mathrm{C}$ in dark (accumulation phase). After washing twice with ice cold PBS, the cell pellets were resuspended in culture medium and incubated for $60 \mathrm{~min}$ at $37^{\circ} \mathrm{C}$ in dark (the efflux phase). Finally, the activity of the ATP-binding cassette (ABC) transporter ABCB1 or MDR1/P-glycoprotein (P-gp) was analyzed by FACS Calibur flow cytometer (BD Biosciences, USA) using FL3 filter. Data obtained from flow cytometric analysis of P-gp function was then analyzed in winMDI data analysis software version 2.8 .

\section{cDNA synthesis and real-time PCR}

The MT-2 cells were treated with $20 \mu \mathrm{M}$ GBA and $4 \mu \mathrm{M}$ ATO alone or in combination at equal concentrations for $48 \mathrm{~h}$. Total RNA was extracted from the treated cells using Tripure isolation reagent (Roche, Germany) according to the manufacturer's instruction. Complementary DNA (cDNA) was then synthesized using reverse transcriptase and random primers according to manufacturer's instruction (Thermo Fisher Scientific, USA). Glyceraldehyde-3-phosphate dehydrogenase (GAPDH) primers were used to control the cDNA synthesis efficacy.

Primers and probes were designed by Allele ID, version 5 after obtaining the desired sequences for genes (RelA, p53, CDK4, c-MYC, c-FLIPL, and c-FLIPS) from the National Center for Biotechnology Information (NCBI) GenBank. Real-time PCR was performed on Rotor gene 6000 cycler (Qiagen, Germany), using TaqMan and SYBR Green reagents (Takara, Japan) according to the manufacturer's instruction. The gene expression of RelA, p53, and CDK4 was evaluated with Taq Man real-time PCR assay and SYBR Green real-time PCR method was performed for c-MYC, c-FLIPL, and c-FLIPS. $\beta 2$ microglobulin $(\beta 2 \mathrm{M})$ was considered as a cellular reference gene in both methods. Table 1 represents specific primers and probes used for detection of desired genes.

\section{Statistical analysis}

Statistical analysis was performed using Statistical Package for Social Sciences (SPSS) software (version 16.0, SPSS, Inc, Chicago, IL, USA).Variables with normal distribution were compared between groups using one-way ANOVA. Bonferroni post-hoc analysis was used for between-group comparisons. Additionally, the relationship between genes was assessed using Spearman's correlation analysis. $P$ values $<0.05$ were considered to be statistically significant. All data were expressed as means \pm standard deviation (SD). 


\section{Results}

\section{GBA exerted cytotoxicity in MT-2 cell line}

We first determined the viability of MT-2 cells treated with various concentrations of GBA (5, 10, 20, 40, and $80 \mu \mathrm{M})$ and/or ATO $(2,4,8$, and $16 \mu \mathrm{M})$ for 24,48 , and $72 \mathrm{~h}$ by alamar blue assay. As shown in Figure 1 , the growth kinetics of GBA-treated MT-2 cells differs from those of solvent treated control cells and the proliferative activity of MT-2 cells decreased after exposure to GBA for 24, 48, and $72 \mathrm{~h}$ compared to the DMSO-treated group. GBA induced the most cytotoxicity on MT-2 cells after 48 hours. These findings indicate that GBA is cytotoxic against MT-2 cells in a dose dependent manner with an IC50 of $80 \mu \mathrm{M}$ at 48 h $(53.3 \%$ cell viability, $\mathrm{P}<0.0001)$. ATO was also cytotoxic to MT-2 cells with an IC50 of $16 \mu \mathrm{M}$ at $72 \mathrm{~h}$ (Data not shown).

\section{Effects of GBA in combination with ATO against MT-2 cells}

In order to study the impact of the combination of GBA and ATO, the viability of MT-2 cells treated with GBA $(5,10$, and $20 \mu \mathrm{M})$ and ATO $(2$ and $4 \mu \mathrm{M})$ was assessed after 24, 48, and 72 h exposure. Our results show that the proliferative activity of MT-2 cells also decreased after 24, 48, and 72 h exposure to the GBA+ATO combinations compared to the control groups (Data not shown). The combination of GBA and ATO was cytotoxic against MT-2 cells in a dose dependent manner and induced the most cytotoxicity on MT-2 cells after 48 hours (Figure 2A). As shown in figure 2B, treatment with the combination of $20 \mu \mathrm{M}$ GBA and $4 \mu \mathrm{M}$ ATO at 48h significantly decreased viability of MT-2 cell (67.3\% viability) compared to 20 $\mu \mathrm{M}$ GBA (90.3\% viability) or $4 \mu \mathrm{M}$ ATO $(98 \%$ viability) alone $(\mathrm{p}<0.0001)$.

\section{GBA in combination with ATO induced sub-G , $_{1}$ phase cells accumulation in MT- 2 cell line}

To identify whether the cytotoxicity of the GBA+ATO combination was mediated by induction of apoptotic cell death, cell cycle analysis was performed. Flow cytometric cell cycle analysis by PI staining, revealed that $20 \mu \mathrm{M}$ GBA in combination with $4 \mu \mathrm{M}$ ATO significantly increased the sub- $\mathrm{G}_{1}$ apoptotic population. As Figure 3 shows, the combination of $20 \mu \mathrm{M}$ GBA and $4 \mu \mathrm{M}$ ATO displayed a significant cell arrest in sub-G ${ }_{1}$ phase $(55.56 \%)$ compared to GBA or ATO alone at equal concentrations $(2.30 \%$ and $4.30 \%$, respectively).

\section{GBA inhibits the P-glycoprotein efflux function in MT-2 cells}

The function of MDR1/P-gp or ABCB1, an ABC drug transporter, was assessed with flow cytometry using mitoxantrone. To study the P-gp function, the MT-2 cells were treated with $20 \mu \mathrm{M}$ GBA for 48 h. Then P-gp-mediated mitoxantrone efflux was assessed. As shown in Figure 4, GBA significantly moved histogram shift to right $(\mathrm{C})$ compared to untreated (A) and DMSO-treated (B) controls. From the shift in fluorescence, it is clear that GBA increased mitoxantrone accumulation in MT-2 cells compared to untreated and DMSOtreated cells $(\mathrm{D})$.

\section{GBA regulated apoptosis related genes in MT-2 cells}

To study the effects of the GBA+ATO combination treatment on the expression of genes involved in regulation of cell cycle, proliferation, and apoptosis in MT-2 cells, real-time PCR was carried out. As shown in Figure 5, the expression of RelA, p53, CDK4, c-MYC, and c-FLIPS genes in GBA-treated MT-2 cells was lower than the DMSO-treated cells but only RelA (0.025 $\pm 0.003, \mathrm{p}<0.0001)$, CDK4 (0.09 \pm 0.006 , $\mathrm{p}<0.0001)$, and $\mathrm{c}-\mathrm{MYC}(0.64 \pm 0.3, \mathrm{p}<0.001)$ expression reached a significant decrease in GBA-treated cells compared with the control $(0.33 \pm 0.005,0.33 \pm 0.02$, and $3.1 \pm 1.02$, respectively). Whereas the gene 
expression of RelA, p53, CDK4, c-MYC, c-FLIPL, and c-FLIPS in GBA+ATO treated cells was dramatically lower than the DMSO-ATO treated cells, only the reduction in the expression of p53 $(0.03 \pm 0.002$, $\mathrm{p}<0.0001)$, CDK4 $(0.2 \pm 0.01, \mathrm{p}<0.0001)$, c-FLIPL $(0.22 \pm 0.1, \mathrm{p}<0.01)$, and c-FLIPS $(0.12 \pm 0.02, \mathrm{p}<$ $0.001)$ genes was statistically significant $(0.22 \pm 0.05,0.5 \pm 0.04,1.6 \pm 0.3$, and $0.9 \pm 0.2)$. In addition, there was a significant positive correlation between the expression of c-FLIPS and p53 $(\mathrm{p}=0.008$ and $\mathrm{r}=0.926)$ (Figure 6).

\section{Discussion}

GBA is a bioactive sesquiterpene coumarin compound isolated fromFerula species (Bedniak, 1962; Iranshahi et al., 2018).Ferula assafoetida and Ferula Szowitsiana, as rich sources of GBA, are herbaceous plants of the genus Ferula belonging to the Umbelliferae family and are distributed throughout central Asia, eastern Iran, and Afghanistan (Abd El-Razek et al., 2001; Iranshahi et al., 2007; Yaqoob and Nawchoo, 2016). GBA is an herbal compound with multiple biological activities including anticancer, cancer chemopreventive, hepatoprotective, and antiviral activities (Bedniak et al., 1967; Syrov et al., 1990; Iranshahi et al., 2008; Iranshahy and Iranshahi, 2011; Kim et al., 2011; Kasaian et al., 2014). GBA exerts its anticancer activity in association with apoptosis induction, P-glycoprotein (P-gp) inhibition, and anti-proliferative actions (HanafiBojd et al., 2011; Kim et al., 2011). The anti-tumor activities of GBA inspired us to investigate the effects of GBA in MT-2 cell line to find if GBA can improve the therapeutic efficacy of ATO, as a potential agent in combination with antivirals and IFN- $\alpha$ in the treatment of ATL (Kchour et al., 2009), and determine whether the GBA+ATO combination could be an effective treatment for patients with ATL.

Results of the present study indicate that GBA is cytotoxic to MT-2 cells in a dose-dependent manner with an IC50 value of $80 \mu \mathrm{M}$ at $48 \mathrm{~h}$. The growth inhibitory effects of GBA have been reported in several studies. Eskandani et al. reported that GBA increases the percentage of early/late apoptotic cells and attenuates the growth rates of OVCAR-3 human ovarian carcinoma cells in a dose- and time-dependent manner with an IC50 of 37, 12.1, and $10 \mu \mathrm{M}$ at 24, 48, and $72 \mathrm{~h}$, respectively (Eskandani et al., 2015a). In another study, Eskandani et al. showed that intact GBA and GBA-loaded solid lipid nanoparticles (GBA-SLNs) inhibited the growth of A549 human lung epithelial carcinoma cells by upregulation of proapoptotic protein caspase 9 and downregulation of antiapoptotic protein Bcl-xL (Eskandani et al., 2015b). Kim et al. in 2011 reported that GBA plays its anticancer effects against human umbilical vein epithelial cells (HUVECs) and Lewig lung cancer (LLC) cells through anti-angiogenic and anti-proliferative activities (Kim et al., 2011). Zhang et al. in 2012 demonstrated that GBA preferentially inhibits the growth of androgen receptor $(\mathrm{AR})^{+}$prostate cancer cells (with an IC50 of approximately $80 \mu \mathrm{M}$ at $72 \mathrm{~h}$ ) compared to $\mathrm{AR}^{-}$prostate cancer cells by downregulating the AR levels and consequent inhibition of AR signaling pathway which is a critical regulator of the $\mathrm{G}_{1} / \mathrm{S}$ transition and important for development and progression of prostate cancer. Additionally, combination of GBA and bicalutamide, an AR antagonist, showed a greater than additive cytotoxicity in LNCaP prostate cancer cells (Zhang et al., 2012). In the current study, we showed that the combination of GBA and ATO was also cytotoxic against MT-2 cells in a dose-dependent manner and induced the most cytotoxicity on MT-2 cells after 48 hours. Indeed, the combination of $20 \mu \mathrm{M}$ GBA and $4 \mu \mathrm{M}$ ATO at $48 \mathrm{~h}$ significantly decreased the proliferative activity of MT-2 cells compared to each agent alone. In accordance with our findings, Kim et al. in 2019 reported a significant dose-dependent cytotoxicity for the combination of GBA and TNF related apoptosis inducing ligand (TRAIL) in resistant H460/R non-small cell lung cancer cells (NSCLCs) (Kim et al., 2019). It was also shown that GBA in combination with nanomicellar curcumin significantly inhibits the growth of murine C26 and human Caco-2 colon carcinoma cells in a dose-dependent manner (Jafari et al., 2019). Results obtained in our study indicate that GBA is able to inhibit MT-2 cells growth specifically when combined with ATO. Cell cycle analysis also showed that GBA or ATO alone induced apoptotic cell death and sub- $\mathrm{G}_{1}$ phase arrest in a low percentage of treated cells (2.30\% and $4.30 \%$, respectively), whereas the combination of GBA and ATO at the equal concentrations significantly increased the sub- $\mathrm{G}_{1}$ apoptotic population (55.56\%). In line with the findings of our study, several reports have indicated that GBA increases sub- $\mathrm{G}_{1}$ apoptotic population. Kim et al. demonstrated that the combination of GBA $(25$ or $50 \mu \mathrm{M})$ and 
TRAIL $(25 \mathrm{ng} / \mathrm{ml})$ in resistant H460/R NSCLCs increased distribution of apoptotic cells in sub-G $\mathrm{G}_{1}$ phase to $24.75 \%$ and $31.09 \%$, respectively, compared with $25 \mu \mathrm{M}$ GBA (6.50\%), $50 \mu \mathrm{M}$ GBA $(12.26 \%$ ), and 25 $\mathrm{ng} / \mathrm{ml}$ TRAIL (11.51\%) (Kim et al., 2019). Oh et al. have also shown that GBA at the concentrations of 25 and $50 \mu \mathrm{M}$ significantly increases sub-G $\mathrm{G}_{1}$ phase cells population in $\mathrm{H} 460$ NSCLCs to $7.71 \%$ and $7.92 \%$, respectively, compared with the untreated control (0.17\%) (Oh et al., 2015). By contrast, Kim et al. have detected no apparent changes in the frequency of GBA-treated LLC cells in the sub-G $\mathrm{G}_{1}$ phase, indicating that GBA could not induce apoptotic cell death in LLC cells. Nevertheless, cell cycle analysis showed that GBA inhibited the LLC cells growth by causing an evident $\mathrm{G}_{2} / \mathrm{M}$ phase arrest (Kim et al., 2011). Contrary to the findings of Kim et al. study, it is clear that the GBA+ATO combination treatment synergistically induced sub- $\mathrm{G}_{1}$ apoptotic population in MT-2 cells.

Pumping therapeutic agents out of cell, mediated by multiple drug efflux transporters of the ATP-binding cassette (ABC) family, is a serious impediment to the effective chemotherapy. Overexpression and enhanced efflux activity of MDR1/P-gp or ABC sub-family B member 1 (ABCB1) have been reported in patients with ATL. It has been also reported that HTLV-1 Tax protein is a potent transcriptional activator of MDR1/Pgp gene promoter. MDR1/P-gp overexpression endows ATL cells with a drug resistance phenotype (Lau et al., 1998). Therapeutic agents with the ability to inhibit the P-gp mediated efflux activity could be used in combination with existing medicines to increase their potency against ATL cells. Several studies have investigated the effects of GBA on MDR-1/P-gp. Studying the effects of GBA on P-gp efflux activity via rhodamine 123 efflux assay in doxorubicin-resistant MCF7/Adr breast cancer cells revealed that GBA is a potent $\mathrm{P}$-gp inhibitor that is more effective in inhibiting the function of $\mathrm{ABCB} 1 / \mathrm{P}$-gp compared to verapamil, a typical P-gp inhibitor (Hanafi-Bojd et al., 2011). Using GBA against six Multi-drug resistance clinical isolates ofStaphylococcus aureus showed that GBA has efflux inhibitory effects on P-gp and its mechanism of action is comparable to verapamil (Bazzaz et al., 2010). In another study, Kim et al. showed that GBA in combination with TRAIL inhibits MDR1 efflux activity by repressing the MDR1 expression in resistant H460/R NSCLCs, thereby leading to enhanced TRAIL-induced apoptosis induction in NSCLCs (Kim et al., 2019). The present study confirms previous findings about GBA inhibitory effect on the functionality of the P-gp efflux pump. Results obtained from efflux assay showed that the rate of MTX accumulation in MT-2 cells increased in the presence of GBA. The enhanced accumulation of MTX in GBA-treated MT-2 cells may be attributed to efflux inhibitory properties of GBA. Therefore, GBA increased intracellular accumulation of ATO in MT-2 cells through inhibition of P-gp efflux activity and therefore could overcome the P-gp mediated Multi-drug resistance and induced apoptotic cell death in MT-2 cells.

The expression levels of genes involved in cell proliferation and apoptosis is altered in ATL, resulting in an increase in cell proliferation and survival and a reduction of apoptosis (Duyao et al., 1992; Mori et al., 1999; Ariumi et al., 2000; Haller et al., 2000; Yoshida, 2001; Sun and Yamaoka, 2005; Krueger et al., 2006). In the present study, we found that the mRNA levels of RelA, CDK4, and c-MYC significantly decreased after treatment with $20 \mu \mathrm{M}$ GBA. However, when combined with $4 \mu \mathrm{M}$ ATO, only the expression levels of CDK4 was downregulated, although, the reduction in CDK4 levels in treatment with GBA alone was greater than the reduction mediated by the GBA+ATO combination. Cyclin dependent kinase 4 (CDK4) mediates $\mathrm{G}_{1} / \mathrm{S}$ cell cycle progression (Sherr and Roberts, 1995). In HTLV-1 infected cells, Tax interacts with inhibitors of CDK activity such as p16INK4A, leading to uncontrolled cell proliferation (Suzuki et al., 1996; Haller et al., 2000; Yoshida, 2001). GBA-mediated downregulation of CDK4 might inhibit transition from $\mathrm{G}_{1}$ phase of cell cycle to $\mathrm{S}$ and therefore induces sub- $\mathrm{G}_{1}$ phase cells accumulation. In addition to CDK4, we also observed reduced expression levels of c-FLIPL and c-FLIPS in cells treated with the GBA+ATO combination, which might associate with induced apoptotic cell death in MT-2 cells. Several studies have reported that high expression levels of c-FLIP supports the cancer cells to elude the immunosurveillance and promotes the tumor cells growth (Djerbi et al., 1999; Medema et al., 1999). Tax expressing HTLV-1 infected T cells express high levels of c-FLIPL and c-FLIPS which contributes to inhibition of apoptosis in infected cells, blocking the receptor mediated cell death, evading the host immune response and supports development of HTLV-1 associated diseases (Krueger et al., 2006; Okamoto et al., 2006). GBA-induced downregulation of c-FLIPL and c-FLIPS in MT-2 cells treated with the GBA+ATO combination could augment death receptor 
mediated apoptosis in MT-2 cells and make them more susceptible to apoptotic cell death.

The GBA+ATO combination unexpectedly decreased the expression levels of the tumor suppressor p53 in MT-2 cells. p53 plays a crucial role in cancer prevention by controlling the cell cycle progression (Ozaki and Nakagawara, 2011; Xu-Monette et al., 2012). In the current study, a significant positive correlation was found between the expression of c-FLIPS and p53. The GBA-mediated downregulation of p53 might be related with the involvement of p53 in c-FLIPS expression (Bartke et al., 2001). c-FLIP contributes to apoptosis resistance. Therefore, treatment with the GBA+ATO combination resulted in downregulation of p53 expression in MT-2 cells and consequently inhibition of the p53-induced upregulation of c-FLIPS and therefore suppression of the c-FLIPS apoptosis inhibitory effects. On this basis, we conclude that apoptosis induction in MT-2 cells seems to be independent of p53 activation. Taken together, GBA+ATO mediated downregulation of p53 and c-FLIPS might lead to induction of death receptor-mediated apoptosis in MT-2 cells.

\section{Conclusion}

The results of the present study have demonstrated that GBA and ATO synergize to inhibit the proliferation of MT-2 cells and induce cell cycle arrest and apoptotic cell death, thus the GBA+ATO combination could be considered as a new therapeutic approach in the treatment of ATL. However, further in vitro and in vivo studies are necessary to elucidate its molecular mechanism of action.

\section{Conflict of Interest}

The authors declare that there are no conflicts of interest.

\section{Acknowledgments}

We would like to express our gratitude and thanks to the Research Council of Mashhad University of Medical Sciences, Mashhad, Iran, for financial support.

\begin{tabular}{lll}
\hline Author Name & Author Email & Contribution to Study \\
\hline Maryam Mahdifar & Mahdifarm951@mums.ac.ir & Investigation, Formal analysis, \\
& & Writing - Original Draft \\
Mehrdad Iranshahi & Iranshahim@mums.ac.ir & Resources \\
Narges Valizadeh & valizadehn1@mums.ac.ir & Formal analysis \\
Marzieh Golizadeh & m.golizadeh186@gmail.com & Editing \\
Fatemeh B. Rassouli & behnam3260@um.ac.ir & Conceptualization, Supervision, \\
& & Review \& Editing, Validation \\
Houshang Rafatpanah & rafatpanahh@mums.ac.ir & Conceptualization, Resources, \\
& & Supervision, Project \\
& & administration, Review \& Editing \\
\hline
\end{tabular}

Data availability statement: The data that support the findings of this study are available from the corresponding author upon reasonable request.

\section{References}

Abd El-Razek, M.H., Ohta, S., Ahmed, A.A., and Hirata, T. (2001). Sesquiterpene coumarins from the roots of Ferula assa-foetida.Phytochemistry 58(8), 1289-1295.

Ariumi, Y., Kaida, A., Lin, J.Y., Hirota, M., Masui, O., Yamaoka, S., et al. (2000). HTLV-1 tax oncoprotein represses the $\mathrm{p} 53$-mediated trans-activation function through coactivator $\mathrm{CBP}$ sequestration. Oncogene 19(12), 1491-1499. doi: 10.1038/sj.onc.1203450. 
Arslan, D., Tural, D., and Akar, E. (2013). Herbal administration and interaction of cancer treatment. $J$ Palliat Med 16(11),1466-1476. doi: 10.1089/jpm.2013.0126.

Bartke, T., Siegmund, D., Peters, N., Reichwein, M., Henkler, F., Scheurich, P., et al. (2001). p53 upregulates cFLIP, inhibits transcription of NF-kappaB-regulated genes and induces caspase-8-independent cell death in DLD-1 cells. Oncogene20(5), 571-580. doi: 10.1038/sj.onc.1204124.

Bazarbachi, A., El-Sabban, M.E., Nasr, R., Quignon, F., Awaraji, C., Kersual, J., et al. (1999). Arsenic trioxide and interferon-alpha synergize to induce cell cycle arrest and apoptosis in human T-cell lymphotropic virus type I-transformed cells. Blood93(1), 278-283.

Bazzaz, B.S., Memariani, Z., Khashiarmanesh, Z., Iranshahi, M., and Naderinasab, M. (2010). Effect of galbanic Acid, a sesquiterpene coumarin from ferula szowitsiana, as an inhibitor of efflux mechanism in resistant clinical isolates of Staphylococcus aureus. Braz J Microbiol 41(3), 574-580. doi: 10.1590/s151783822010000300006.

Bedniak, A. (1962). On the problem of the isolation of galbanic acid from Ferula gumosa Boiss. roots. Aptechnoe delo 12,28-34.

Bedniak, A.E., Pershin, G.N., and Milovanova, S.N. (1967). [Antibacterial activity of galbanic acid and of its conversion products]. Farmatsiia 16(4), 45-49.

Djerbi, M., Screpanti, V., Catrina, A.I., Bogen, B., Biberfeld, P., and Grandien, A. (1999). The inhibitor of death receptor signaling, FLICE-inhibitory protein defines a new class of tumor progression factors. Journal of Experimental Medicine 190(7),1025-1032.

Duyao, M., Kessler, D., Spicer, D., Bartholomew, C., Cleveland, J., Siekevitz, M., et al. (1992). Transactivation of the c-myc promoter by human T cell leukemia virus type 1 tax is mediated by NF kappa B.Journal of Biological Chemistry 267(23), 16288-16291.

El-Sabban, M.E., Nasr, R., Dbaibo, G., Hermine, O., Abboushi, N., Quignon, F., et al. (2000). Arsenicinterferon-alpha-triggered apoptosis in HTLV-I transformed cells is associated with tax down-regulation and reversal of NF-kappa B activation. Blood 96(8),2849-2855.

Eskandani, M., Abdolalizadeh, J., Hamishehkar, H., Nazemiyeh, H., and Barar, J. (2015a). Galbanic acid inhibits HIF-1 $\alpha$ expression via EGFR/HIF-1 $\alpha$ pathway in cancer cells. Fitoterapia 101,1-11.

Eskandani, M., Barar, J., Dolatabadi, J.E., Hamishehkar, H., and Nazemiyeh, H. (2015b). Formulation, characterization, and geno/cytotoxicity studies of galbanic acid-loaded solid lipid nanoparticles. Pharm Biol 53(10), 1525-1538. doi: 10.3109/13880209.2014.991836.

Haller, K., Ruckes, T., Schmitt, I., Saul, D., Derow, E., and Grassmann, R. (2000). Tax-dependent stimulation of G1 phase-specific cyclin-dependent kinases and increased expression of signal transduction genes characterize HTLV type 1-transformed T cells. AIDS Res Hum Retroviruses 16(16), 1683-1688. doi: $10.1089 / 08892220050193146$.

Hanafi-Bojd, M.Y., Iranshahi, M., Mosaffa, F., Tehrani, S.O., Kalalinia, F., and Behravan, J. (2011). Farnesiferol A from Ferula persica and galbanic acid from Ferula szowitsiana inhibit P-glycoprotein-mediated rhodamine efflux in breast cancer cell lines. Planta Med77(14), 1590-1593. doi: 10.1055/s-0030-1270987.

Hermine, O., Ramos, J.C., and Tobinai, K. (2018). A Review of New Findings in Adult T-cell LeukemiaLymphoma: A Focus on Current and Emerging Treatment Strategies. Adv Ther 35(2), 135-152. doi: 10.1007/s12325-018-0658-4.

Hironaka, N., Mochida, K., Mori, N., Maeda, M., Yamamoto, N., and Yamaoka, S. (2004). Taxindependent constitutive IkappaB kinase activation in adult T-cell leukemia cells. Neoplasia6(3), 266-278. doi: $10.1593 /$ neo.3388. 
Horie, R. (2007). NF-kappaB in pathogenesis and treatment of adult T-cell leukemia/lymphoma. Int Rev Immunol 26(5-6),269-281. doi: 10.1080/08830180701703364.

Iranshahi, M., Arfa, P., Ramezani, M., Jaafari, M.R., Sadeghian, H., Bassarello, C., et al. (2007). Sesquiterpene coumarins from Ferula szowitsiana and in vitro antileishmanial activity of 7-prenyloxycoumarins against promastigotes. Phytochemistry68(4), 554-561.

Iranshahi, M., Kalategi, F., Rezaee, R., Shahverdi, A.R., Ito, C., Furukawa, H., et al. (2008). Cancer chemopreventive activity of terpenoid coumarins from Ferula species. Planta Med74(2), 147-150. doi: $10.1055 / \mathrm{s}-2008-1034293$.

Iranshahi, M., Rezaee, R., Najafi, M.N., Haghbin, A., and Kasaian, J. (2018). Cytotoxic activity of the genus Ferula (Apiaceae) and its bioactive constituents. Avicenna journal of phytomedicine8(4), 296.

Iranshahy, M., and Iranshahi, M. (2011). Traditional uses, phytochemistry and pharmacology of asafoetida (Ferula assa-foetida oleo-gum-resin) - A review. Journal of ethnopharmacology134(1), 1-10.

Ishitsuka, K., Hanada, S., Suzuki, S., Utsunomiya, A., Chyuman, Y., Takeuchi, S., et al. (1998). Arsenic trioxide inhibits growth of human T-cell leukaemia virus type I infected T-cell lines more effectively than retinoic acids. British journal of haematology103(3), 721-728.

Ishitsuka, K., Ikeda, R., Utsunomiya, A., Uozumi, K., Hanada, S., Suzuki, S., et al. (2002). Arsenic trioxide induces apoptosis in HTLV-I infected T-cell lines and fresh adult T-cell leukemia cells through CD95 or tumor necrosis factor alpha receptor independent caspase activation. Leuk Lymphoma 43(5), 1107-1114.

Jafari, A., Teymouri, M., Nik, M.E., Abbasi, A., Iranshahi, M., Hanafi-Bojd, M.Y., et al. (2019). Interactive anticancer effect of nanomicellar curcumin and galbanic acid combination therapy with some common chemotherapeutics in colon carcinoma cells. Avicenna journal of phytomedicine 9(3), 237.

Kasaian, J., Iranshahy, M., and Iranshahi, M. (2014). Synthesis, biosynthesis and biological activities of galbanic acid-A review.Pharmaceutical biology 52(4), 524-531.

Kashanchi, F., and Brady, J.N. (2005). Transcriptional and post-transcriptional gene regulation of HTLV-1. Oncogene24(39), 5938-5951. doi: 10.1038/sj.onc.1208973.

Kchour, G., Rezaee, R., Farid, R., Ghantous, A., Rafatpanah, H., Tarhini, M., et al. (2013). The combination of arsenic, interferon-alpha, and zidovudine restores an "immunocompetent-like" cytokine expression profile in patients with adult T-cell leukemia lymphoma. Retrovirology 10, 91. doi: 10.1186/1742-4690-10-91.

Kchour, G., Tarhini, M., Kooshyar, M.M., El Hajj, H., Wattel, E., Mahmoudi, M., et al. (2009). Phase 2 study of the efficacy and safety of the combination of arsenic trioxide, interferon alpha, and zidovudine in newly diagnosed chronic adult T-cell leukemia/lymphoma (ATL).Blood 113(26), 6528-6532. doi: 10.1182/blood-2009-03-211821.

Kim, K.H., Lee, H.J., Jeong, S.J., Lee, H.J., Lee, E.O., Kim, H.S., et al. (2011). Galbanic acid isolated from Ferula assafoetida exerts in vivo anti-tumor activity in association with anti-angiogenesis and antiproliferation. Pharm Res 28(3), 597-609. doi: 10.1007/s11095-010-0311-7.

Kim, Y.H., Shin, E.A., Jung, J.H., Park, J.E., Koo, J., Koo, J.I., et al. (2019). Galbanic acid potentiates TRAIL induced apoptosis in resistant non-small cell lung cancer cells via inhibition of MDR1 and activation of caspases and DR5. European journal of pharmacology847, 91-96.

Krueger, A., Fas, S.C., Giaisi, M., Bleumink, M., Merling, A., Stumpf, C., et al. (2006). HTLV-1 Tax protects against CD95-mediated apoptosis by induction of the cellular FLICE-inhibitory protein (c-FLIP).Blood 107(10), 3933-3939. doi: 10.1182/blood-2005-06-2567.

Lau, A., Nightingale, S., Taylor, G.P., Gant, T.W., and Cann, A.J. (1998). Enhanced MDR1 gene expression in human T-cell leukemia virus-I-infected patients offers new prospects for therapy. Blood91(7), 2467-2474. 
Mahieux, R., Pise-Masison, C., Gessain, A., Brady, J.N., Olivier, R., Perret, E., et al. (2001). Arsenic trioxide induces apoptosis in human T-cell leukemia virus type 1- and type 2-infected cells by a caspase-3dependent mechanism involving Bcl-2 cleavage. Blood98(13), 3762-3769.

Matsuoka, M., and Jeang, K.-T. (2007). Human T-cell leukaemia virus type 1 (HTLV-1) infectivity and cellular transformation. Nature Reviews Cancer 7(4), 270-280.

Medema, J.P., de Jong, J., van Hall, T., Melief, C.J., and Offringa, R. (1999). Immune escape of tumors in vivo by expression of cellular FLICE-inhibitory protein. Journal of Experimental Medicine190(7), 1033-1038.

Mori, N., Fujii, M., Ikeda, S., Yamada, Y., Tomonaga, M., Ballard, D.W., et al. (1999). Constitutive activation of NF-kappaB in primary adult T-cell leukemia cells. Blood 93(7), 2360-2368.

Mulloy, J.C., Kislyakova, T., Cereseto, A., Casareto, L., LoMonico, A., Fullen, J., et al. (1998). Human T-cell lymphotropic/leukemia virus type 1 Tax abrogates p53-induced cell cycle arrest and apoptosis through its CREB/ATF functional domain. J Virol 72(11), 8852-8860.

Oh, B.S., Shin, E.A., Jung, J.H., Jung, D.B., Kim, B., Shim, B.S., et al. (2015). Apoptotic effect of galbanic acid via activation of caspases and inhibition of Mcl-1 in H460 non-small lung carcinoma cells. Phytotherapy Research 29(6), 844-849.

Okamoto, K., Fujisawa, J., Reth, M., and Yonehara, S. (2006). Human T-cell leukemia virus type-I oncoprotein Tax inhibits Fas-mediated apoptosis by inducing cellular FLIP through activation of NF-kappaB.Genes Cells 11(2), 177-191. doi: 10.1111/j.1365-2443.2006.00927.x.

Ozaki, T., and Nakagawara, A. (2011). p53: the attractive tumor suppressor in the cancer research field. $J$ Biomed Biotechnol2011, 603925. doi: 10.1155/2011/603925.

Portis, T., Grossman, W.J., Harding, J.C., Hess, J.L., and Ratner, L. (2001). Analysis of p53 inactivation in a human T-cell leukemia virus type 1 Tax transgenic mouse model. $J$ Virol 75(5),2185-2193. doi: 10.1128/jvi.75.5.2185-2193.2001.

Ressler, S., Morris, G.F., and Marriott, S.J. (1997). Human T-cell leukemia virus type 1 Tax transactivates the human proliferating cell nuclear antigen promoter. J Virol 71(2), 1181-1190.

Romeo, M.M., Ko, B., Kim, J., Brady, R., Heatley, H.C., He, J., et al. (2015). Acetylation of the c-MYC oncoprotein is required for cooperation with the HTLV-1 p30(II) accessory protein and the induction of oncogenic cellular transformation by p30(II)/c-MYC. Virology 476,271-288. doi: 10.1016/j.virol.2014.12.008.

Schmitt, I., Rosin, O., Rohwer, P., Gossen, M., and Grassmann, R. (1998). Stimulation of cyclindependent kinase activity and G1- to S-phase transition in human lymphocytes by the human T-cell leukemia/lymphotropic virus type 1 Tax protein. J Virol72(1), 633-640.

Sherr, C.J., and Roberts, J.M. (1995). Inhibitors of mammalian G1 cyclin-dependent kinases. Genes Dev 9(10), 1149-1163. doi: 10.1101/gad.9.10.1149.

Sun, S.C., and Yamaoka, S. (2005). Activation of NF-kappaB by HTLV-I and implications for cell transformation. Oncogene 24(39),5952-5964. doi: 10.1038/sj.onc.1208969.

Suzuki, T., Kitao, S., Matsushime, H., and Yoshida, M. (1996). HTLV-1 Tax protein interacts with cyclindependent kinase inhibitor p16INK4A and counteracts its inhibitory activity towards CDK4. The EMBO journal 15(7), 1607-1614.

Syrov, V.N., Khushbaktova, Z.A., and Nabiev, A.N. (1990). [The effect of galbanic acid on the course of experimental hepatitis].Farmakol Toksikol 53(2), 41-43.

Tanaka, A., Takahashi, C., Yamaoka, S., Nosaka, T., Maki, M., and Hatanaka, M. (1990). Oncogenic transformation by the tax gene of human T-cell leukemia virus type I in vitro. Proceedings of the National Academy of Sciences 87(3), 1071-1075. 
Tsukasaki, K., and Tobinai, K. (2012). Clinical Trials and Treatment of ATL. Leuk Res Treatment 2012, 101754. doi: $10.1155 / 2012 / 101754$.

Wang, C.Z., Calway, T., and Yuan, C.S. (2012). Herbal medicines as adjuvants for cancer therapeutics. Am $J$ Chin Med 40(4),657-669. doi: 10.1142/s0192415x12500498.

Xu-Monette, Z.Y., Medeiros, L.J., Li, Y., Orlowski, R.Z., Andreeff, M., Bueso-Ramos, C.E., et al. (2012). Dysfunction of the TP53 tumor suppressor gene in lymphoid malignancies. Blood 119(16),3668-3683. doi: 10.1182/blood-2011-11-366062.

Yaqoob, U., and Nawchoo, I.A. (2016). Distribution and taxonomy of Ferula L.-a review. RRJOB 5(3), 15-23.

Yasunami, T., Wang, Y.H., Tsuji, K., Takanashi, M., Yamada, Y., and Motoji, T. (2007). Multidrug resistance protein expression of adult T-cell leukemia/lymphoma. Leuk Res 31(4), 465-470. doi: 10.1016/j.leukres.2006.10.012.

Yoshida, M. (2001). Multiple viral strategies of HTLV-1 for dysregulation of cell growth control. Annu Rev Immunol19, 475-496. doi: 10.1146/annurev.immunol.19.1.475.

Zane, L., Yasunaga, J., Mitagami, Y., Yedavalli, V., Tang, S.W., Chen, C.Y., et al. (2012). Wip1 and p53 contribute to HTLV-1 Tax-induced tumorigenesis. Retrovirology 9, 114. doi: 10.1186/1742-4690-9-114.

Zhang, L.-l., Wei, J.-y., Wang, L., and Chen, J.-l. (2017). Human T-cell lymphotropic virus type 1 and its oncogenesis. Acta Pharmacologica Sinica 38(8), 1093.

Zhang, Y., Kim, K.H., Zhang, W., Guo, Y., Kim, S.H., and Lu, J. (2012). Galbanic acid decreases androgen receptor abundance and signaling and induces G1 arrest in prostate cancer cells. Int J Cancer130(1), 200212. doi: $10.1002 /$ ijc.25993.

Table 1. Primer and probe sequences and amplicon lengths

\begin{tabular}{|c|c|c|c|}
\hline Name & Primer Name & Sequence (5'-3') & Product Length(bp) \\
\hline \multirow{2}{*}{$\mathrm{c}-\mathrm{myc}$} & Forward & ACTCTGAGGAGGAACAAGAA & 159 \\
\hline & Reverse & TGGAGACGTGGCACCTCTT & \\
\hline \multirow{2}{*}{ c-FLIPL } & Forward & ATTGGCAATGAGACAGAGCTTC & 126 \\
\hline & Reverse & CTCGGGCATACAGGCAAA & \\
\hline \multirow[t]{2}{*}{ c-FLIPS } & Forward & CCAGAAGTACAAGCAGTCTGTTC & 122 \\
\hline & Reverse & GGGCATAGGGTGTTATCATCC & \\
\hline \multirow[t]{3}{*}{ RelA } & Forward & ACCCCTTCCAAGTTCCTATAGAAGAG & 145 \\
\hline & Reverse & CGATTGTCAAAGATGGGATGAGAAAG & \\
\hline & Probe & ACTACGACCTGAATGCTGTGCGGCTCTG & \\
\hline \multirow[t]{3}{*}{$\mathrm{p} 53$} & Forward & CAGCATCTTATCCGAGTGGAAGG & \\
\hline & Reverse & GTTGTAGTGGATGGTGGTACAGTC & 132 \\
\hline & Probe & CTCAGGCGGCTCATAGGGCACCAC & \\
\hline \multirow[t]{3}{*}{ CDK4 } & Forward & AAATTGGTGTCGGTGCCTATGG & \\
\hline & Reverse & CACGAACTGTGCTGATGGGAAG & 135 \\
\hline & Probe & ACAAGGCCCGTGATCCCCACAGTGG & \\
\hline \multirow{3}{*}{ B2M } & Forward & TTGTCTTTCAGCAAGGACTGG & 127 \\
\hline & Reverse & CCACTTAACTATCTTGGGCTGTG & \\
\hline & Probe & TCACATGGTTCACACGGCAGGCAT & \\
\hline
\end{tabular}

Figure 1. Time-based dose response analysis of MT-2 cells to GBA after 24,48 , and $72 \mathrm{~h}$. The MT-2 cell line was treated with various concentrations of GBA $(5,10,20,40$, and $80 \mu \mathrm{M})$ for 24,48 , and $72 \mathrm{~h}$. The cell viability was assessed with alamar blue assay. Viability assessment was carried for at least three times 
and results are presented as mean \pm SD. MT-2 cells treated with $0.5 \%$ DMSO were considered as relevant control. Statistical significance from control; ${ }^{*} \mathrm{P}<0.05,{ }^{* *} \mathrm{P}<0.01,{ }^{* * *} \mathrm{P}<0.001$, and ${ }^{* * * *} \mathrm{P}<0.0001$.

Figure 2. (A) Viability of MT-2 cells after treatment with various concentrations of GBA and ATO at 48 h. In each combination, cells treated with $0.5 \%$ DMSO-ATO (with similar dose) were considered as relevant control. (B)Viability of MT-2 cells significantly decreased after treatment with $20 \mu \mathrm{M}$ GBA in combination with $4 \mu \mathrm{M}$ ATO after $48 \mathrm{~h}$ compared to treatment with each agent alone at equal concentrations. Viability assessment was carried for at least three times and results are presented as mean \pm SD. Statistical significance from control; $* \mathrm{P}<0.05,{ }^{* *} \mathrm{P}<0.01,{ }^{* * *} \mathrm{P}<0.001$, and $^{* * * *} \mathrm{P}<0.0001$.

Figure 3. Effects of GBA/ATO on apoptotic cell death in MT-2 cell line. The MT-2 cells were treated with 20 $\mu \mathrm{M}$ GBA and $4 \mu \mathrm{M}$ ATO alone or in combination for $48 \mathrm{~h}$ and stained with PI. Then the sub-G population was analyzed by flow cytometry. PI staining reveals distribution of cells in four major phases of cell cycle including, sub- $\mathrm{G}_{1}, \mathrm{G}_{1}, \mathrm{~S}$, and G2/M. (A) Untreated, (B) 0.5\% DMSO-treated, (C) $20 \mu \mathrm{M}$ GBA-treated, (D) $4 \mu \mathrm{M}$ ATO-treated, (E) $4 \mu \mathrm{M}$ 0.5\% DMSO-ATO-treated, and (F) $20 \mu \mathrm{M}$ GBA-4 $\mu \mathrm{M}$ ATO-treated cells.

Figure 4. Flow cytometric analysis of Mitoxantrone uptake and efflux by MT-2 cells. P-gp function was assayed by flow cytometry in MT-2 cells after exposure to $10 \mu$ Mmitoxantrone. As shown by the shift in fluorescence, GBA decreased mitoxantrone efflux in MT-2 cells (C) compared to Untreated (A) and DMSOtreated (B) cells.

Figure 5. The mRNA expression levels of (A) RelA, (B) p53, (C) CDK4, (D) c-MYC, (E) c-FLIPL, and (F) c-FLIPS in MT-2 cells treated with $20 \mu \mathrm{M}$ GBA and $4 \mu \mathrm{M}$ ATO alone and in combination. Statistical significance from control, ${ }^{*} \mathrm{P}<0.05,{ }^{* *} \mathrm{P}<0.01,{ }^{* * *} \mathrm{P}<0.001$, and ${ }^{* * * *} \mathrm{P}<0.0001$.

Figure 6. Pearson's correlation analysis of the expression of p53 and c-FLIPS in 6 groups of MT-2 cells treated with $20 \mu \mathrm{M}$ GBA and/or $4 \mu \mathrm{M}$ ATO alone and in combination.

\section{Hosted file}

Figure 1.docx available at https://authorea.com/users/299916/articles/429486-evaluatingcombinatorial-effects-of-galbanic-acid-and-arsenic-trioxide-on-atl-cells

\section{Hosted file}

Figure 2.docx available at https://authorea.com/users/299916/articles/429486-evaluatingcombinatorial-effects-of-galbanic-acid-and-arsenic-trioxide-on-atl-cells

\section{Hosted file}

Figure 3.docx available at https://authorea.com/users/299916/articles/429486-evaluatingcombinatorial-effects-of-galbanic-acid-and-arsenic-trioxide-on-atl-cells

\section{Hosted file}

Figure 4.docx available at https://authorea.com/users/299916/articles/429486-evaluatingcombinatorial-effects-of-galbanic-acid-and-arsenic-trioxide-on-atl-cells

\section{Hosted file}

Figure 5.docx available at https://authorea.com/users/299916/articles/429486-evaluatingcombinatorial-effects-of-galbanic-acid-and-arsenic-trioxide-on-atl-cells

\section{Hosted file}

Figure 6.docx available at https://authorea.com/users/299916/articles/429486-evaluatingcombinatorial-effects-of-galbanic-acid-and-arsenic-trioxide-on-atl-cells 